NP54 (continued)

from each state are responsible for creating and implementing one nutrition and one physical activity program addressing overweight and obesity among 6-8th grade youth.

Evaluation: Using mixed method baseline data, a questionnaire was developed, disseminated to youth in the six communities and analyzed to capture youth health behaviors, determinants of behaviors, and youth engagement and empowerment prior to program intervention.

Conclusions and Implications: Identifying a potential framework for creating community-focused, sustainable and effective adolescent obesity prevention programs.

Funding: USDA Grant \#2012-68001-19619, Agriculture and Food Research Initiative.

\section{NP55 The Pennsylvania State University Childhood Obesity Prevention Graduate Training Transdisciplinary Program}

Barbara Rolls, PhD, bjr4@psu.edu, Pennsylvania State University, 226 Henderson Building, University Park, PA 16802; J. Savage Williams, PhD; K. L. Keller, PhD;

G. Jensen, $M D, P h D$

Objective: This training program prepares pre-doctoral fellows for careers in childhood obesity prevention through transdisciplinary coursework, research, and internships.

Description: This program includes programmatic areas: nutritional sciences, child development and family studies, prevention and intervention, and research methodology and statistics.

Evaluation: Evaluation is accomplished through yearly external advisory meetings, program evaluation from trainees, ongoing publications and professional accomplishments of trainees, and biweekly meetings of key personnel.
Conclusions and Implications: 13 fellows have produced 51 presentations and 13 publications in the first 4 years of the program.

Funding: USDA Grant \#2011-67001-30117, Pennsylvania State University Matching Funds.

\section{NP56 "Get Fruved:" A Peer-Led, Trained-the- Trainer Social Marketing Intervention to Increase Fruit and Vegetable Intake and Prevent Childhood Obesity}

Sarah Colby,PhD, RD, scolby1@mail.tennessee.edu, University of Tennessee, Department of Nutrition, 1215

W. Cumberland Avenue, 229 Jessie Harris Building, Knoxville, TN 37996-1920; K. Kattelmann, PhD, RDN, LN, South Dakota State University; M. Olfert, DrPH, MS, RDN, LDN, West Virginia University; A. Mathews, PhD, RD, University of Florida; T. Kidd, $P h D, R D, L P N$, Kansas State University; O. Brown, PhD, RD, Auburn University; T. Horacek, PhD, RD, Syracuse University; A. White, PhD, $R D$, University of Maine

Objective: Community based participatory research (CBPR) was used on university campuses to develop peerled, social marketing and environment change interventions to aid students in preventing obesity through improved overall wellness.

Description: Students $(n=323)$ from four treatment universities participated in courses where they co-created interventions (with 154 student researchers and 42 researchers) and learned about peer mentoring.

Evaluation: Treatment students along with control students $(n=100)$ at four universities were assessed on a wide range of health-related factors. Campus environments $(n=8)$ were audited.

Conclusions and Implications: Assessment data are being analyzed. Campus-specific interventions were successfully designed using CPBR.

Funding: USDA Grant \#2014-67001-21851-A2101. 